\section{A content analysis of hospitality research's research methods in the 2010s}

\author{
Cass Shum, Jaimi Garlington, Ankita Ghosh and Seyhmus Baloglu \\ William F. Harrah College of Hospitality, University of Nevada, Las Vegas, \\ Las Vegas, Nevada, USA
}

\begin{abstract}
Purpose - This study aims to describe the development of hospitality research in terms of research methods and data sources used in the 2010 s.

Design/methodology/approach - Content analyses of the research methods and data sources used in original hospitality research published in the 2010s in the Cornell Hospitality Quarterly (CQ), International Journal of Hospitality Management (IJHM), International Journal of Contemporary Hospitality Management (IJCHM), Journal of Hospitality and Tourism Research (JHTR) and International Hospitality Review (IHR) were conducted. It describes whether the time span, functional areas and geographic regions of data sources were related to the research methods and data sources.

Findings - Results from 2,759 original hospitality empirical articles showed that marketing research used various research methods and data sources. Most finance articles used archival data, while most human resources articles used survey designs with organizational data. In addition, only a small amount of research used data from Oceania, Africa and Latin America.

Research limitations/implications - This study sheds some light on the development of hospitality research in terms of research method and data source usage. However, it only focused on five English-based journals from 2010-2019. Therefore, future studies may seek to understand the impact of the COVID-19 pandemic on research methods and data source usage in hospitality research.

Originality/value - This is the first study to examine five hospitality journals' research methods and data sources used in the last decade. It sheds light on the development of hospitality research in the previous decade and identifies new hospitality research avenues.
\end{abstract}

Keywords Research method, Hospitality research, Content analysis, Functional areas, Geographic regions Paper type Research paper

\section{Introduction}

Hospitality research has developed rapidly in the 2010s. Changes in economic, social and technological factors - including postrecession economic recovery, growth of the sharing economy, globalization and evolution in technology - have increased the number of hospitality research publications, changes in research topics and development in research methods and analytical techniques (e.g. Law et al., 2012). There is also an increased emphasis on research rigor with a few recent content analyses studies analyzing analytical techniques (e.g. Cheah et al., 2018; Xu and Martinez, 2018), research biases (e.g. Min et al., 2016; Yüksel, 2017) and bibliometrics (e.g. Cunill et al., 2019; García-Lillo et al., 2016; Köseoglu et al., 2016; Köseoglu et al., 2015).

Despite these developments, much less attention in the last decade has been paid to examine hospitality empirical research methods - the tools and means (e.g. experiments,

(C) Cass Shum, Jaimi Garlington, Ankita Ghosh and Seyhmus Baloglu. Published in International Hospitality Review. Published by Emerald Publishing Limited. This article is published under the Creative Commons Attribution (CC BY 4.0) licence. Anyone may reproduce, distribute, translate and create derivative works of this article (for both commercial and non-commercial purposes), subject to full attribution to the original publication and authors. The full terms of this licence may be seen at http:// creativecommons.org/licences/by/4.0/legalcode
Research method of hospitality research

Received 14 March 2021 Revised 7 July 2021 1 October 2021 
surveys and qualitative designs) researchers use to collect data to uncover new knowledge. A well-designed method ensures that hospitality research findings are not only valid but can also yield trustworthy practical implications to hospitality managers (McKercher, 2018). Accordingly, the research methods employed have often been suggested as an indicator to assess maturity, paradigm, sophistication, quality and progress of a discipline (e.g. Baloglu and Assante, 1999; Köseoglu et al., 2016; Rivera and Upchurch, 2008). However, the lack of recent content analysis of the research methods used in hospitality research hinders our understanding of the current state of hospitality research or ways to improve its sophistication level.

Indeed, the recent development of technology has facilitated new research methods, such as user-generated data (e.g. online review), web data (e.g. hotel pricing data on websites) and simulation (Stamolampros et al., 2020; Lu and Stepchenkova, 2015). Compared with traditional research methods (e.g. survey and experiment), these new methods are available to hospitality managers and researchers at a low cost (Lu and Stepchenkova, 2015). Technology also facilitates new data sources (e.g. online panels) (Aguinis et al., 2021). More importantly, hospitality is a broad field with different functional areas (including marketing, finance, strategy, operations, technology and human resources [HR]) covering multiple geographic regions (including North America, Europe, Asia, Oceania, Latin America, Africa and multiregion) (Baloglu and Assante, 1999; Shen et al., 2018). Yet, the education and preference in research methods in each function area and geographic region can differ (Ali et al., 2021; Amarante, 2014; Mehmetoglu, 2004; Shen et al., 2018). Therefore, a description of research methods and data sources by each functional area and geographic region can enhance validity and pinpoint specific areas that need further development (Shen et al., 2018).

As we progress to the new decade of the $2020 \mathrm{~s}$, it is time to take stock of the research method used in the 2010s and look forward to new opportunities. To ensure the findings can be comparable to the content analysis of research methods conducted by Baloglu and Assante (1999), we focused the content analysis on the five established hospitality journals, including the Cornell Hospitality Quarterly (CQ), International Journal of Hospitality Management (IJHM), International Journal of Contemporary Hospitality Management (IJCHM), Journal of Hospitality and Tourism Research (JHTR) and International Hospitality Review (IHR, formerly the FIU Hospitality Review). This content analysis focused on the research methods and data sources used in original hospitality empirical articles published in these five journals in 2010-2019 by (1) time span, (2) functional areas and (3) geographic regions of the data. It provides implications on the development of hospitality research in the last decade, identifies new avenues of study designs for functional areas and sheds light on potential collaboration opportunities and education and training for academia in different geographic regions. In the next section, we present a brief review of content analyses within the boundaries of hospitality.

\section{Content analyses of research methods in hospitality \\ Research methods}

Scholarly works have used content or bibliometric analyses to reveal the type of research (qualitative versus quantitative), research designs, measurement, sampling and statistical techniques used in hospitality research articles (e.g. Baloglu and Assante, 1999; Chon et al., 1989; Crawford-Welch and McCleary, 1992; Mehmetoglu, 2004; Palmer et al., 2005; Rivera and Upchurch, 2008). Previous content analysis of research methods (Baloglu and Assante, 1999; Law et al., 2012; Line and Runyan, 2012; Yoo et al., 2011) suggested six major methods, including (1) surveys, (2) experiments, (3) qualitative studies, (4) archival data, (5) objective data and (6) simulations. Previous recommendations (Fong et al., 2016) further categorized experiments into (1) scenarios, (2) fields and (3) quasi-experiments. Similarly, past studies (e.g. 
Arendt et al., 2012) further classify qualitative studies into (1) structured questionnaires, (2) interviews and (3) focus groups and refined archival data into (1) printed materials (2) public data, (3) website data and (4) user-generated data. Some researchers also use multiple studies with mixed research methods to balance different research methods' strengths and weaknesses (Mariani and Baggio, 2020; Truong et al., 2020).

Historically, survey research has dominated hospitality research (Baloglu and Assante, 1999). From 1967 to 2005 , there were increasing empirical research articles over time, with 60 $80 \%$ of the empirical hospitality publications using surveys (Baloglu and Assante, 1999; Chon et al., 1989; Rivera and Upchurch, 2008). Such findings were in line with Dolnicar (2018), which showed the popularity of surveys in high-impact hospitality research in 2017. However, field development, editorial decisions and calls from prolific scholars can change the research method usage patterns. For example, former CQ Editor Michael Lynn has called for mix-method studies to "establish the generalizability of effects" (Lynn, 2017, p. 228). This echoes with the development outside hospitality (e.g. information systems, organizational development and strategic management), which requires multiple studies to validate the findings (Elbanna and Gherib, 2012; Olsen, 2019; Venkatesh et al., 2013). Similarly, there were rekindled interests in qualitative studies, as evidenced by calls from scholars (e.g. Arendt et al., 2012) and the creation of a special qualitative column in IJHM in 2018 (Elsevier, 2017). There were also calls for experiments as a tool to show causal relationships (Fong et al., 2016; Mattila, 2004). Recent technology development has facilitated new research methods (e.g. user-generated data, web data and simulation), reducing reliance on surveys (Lu and Stepchenkova, 2015). For example, user-generated data dramatically increased from 1 article in 2001 to 33 articles in 2012 (Lu and Stepchenkova, 2015). Accordingly, hospitality research method usage might have changed considerably since the last review in the 1990s (Baloglu and Assante, 1999, which revealed the research patterns in five hospitality journals as in this study) and 2000s (e.g. Rivera and Upchurch, 2008, which focused on IJHM articles). In short, we ask

$R Q 1$. What were the research methods used in the 2010s?

\section{Data sources}

Although each research method diverges in its ability to test causal relationships (Baloglu and Assante, 1999), data sources and samples also impact the external (i.e. generalizability and realism) and internal validity (i.e. measurement precision) of the findings. The strengths and weaknesses of each method are summarized in Table 1. However, such discussions are based on assumptions of the use of specific data sources. For example, Baloglu and Assante (1999) suggest that survey research can have high external validity if researchers use an effective sampling strategy. Similarly, because it is generally assumed that experiments use convenience samples with scenario experiments, scholars argue that experiments demonstrate causality at the cost of realism (Fong et al., 2016; Mattila, 2004). With the assumption of using a small sample based on personal contact and snowballing sampling techniques, qualitative studies are commonly touted for providing rich data with a high level of realism at the cost of measurement precision and generalizability (Arendt et al., 2012; Walsh, 2003). Archival studies mostly use publicly available data, which results in a high level of context realism and a low level of measurement flexibility (Jones, 2010).

However, technology facilitates the use of online research panels (e.g. Amazon's MTurk) and video conferences (e.g. Zoom), which lowered the cost for both quantitative (Stritch et al., 2017) and qualitative studies (Richard et al., 2018). It also changes previous assumptions of data sources used for specific research methods. For example, although online panels (e.g. MTurk) provide cheap and diverse data sources that can be used for both surveys and experiments, they may not represent the population (Aguinis et al., 2021). There are also 


\section{IHR}

\begin{tabular}{|c|c|c|}
\hline $\begin{array}{l}\text { Research } \\
\text { methods }\end{array}$ & Advantages & Disadvantages \\
\hline Mixed method & $\begin{array}{l}\text { - Helps in addressing the weaknesses of } \\
\text { each research method involved }\end{array}$ & - Requires more time \\
\hline Survey & $\begin{array}{l}\text { - Short turnaround of results } \\
\text { - Typically cost less } \\
\text { - Researchers can contact participants } \\
\text { who might otherwise be inaccessible } \\
\text { - Can cover sensitive topics } \\
\text { - The anonymity of respondents is high } \\
\text { - Results are generalizable }\end{array}$ & $\begin{array}{l}\text { - Possibility for respondents } \\
\text { misunderstanding a question is high } \\
\text { - Requires highly standardized questionnaire } \\
\text { format } \\
\text { - Deliberate falsification-occasionally, people } \\
\text { deliberately give false answers } \\
\text { - Acquiescence bias } \\
\text { - Extremity bias } \\
\text { - Callback or follow-up with respondents is } \\
\text { difficult }\end{array}$ \\
\hline $\begin{array}{l}\text { Scenario } \\
\text { experiment }\end{array}$ & $\begin{array}{l}\text { - Low cost } \\
\text { - Data collection is fast }\end{array}$ & $\begin{array}{l}\text { - Scenarios are open to respondent's } \\
\text { interpretation } \\
\text { - Low level of control }\end{array}$ \\
\hline Field experiment & $\begin{array}{l}\text { - Researcher's ability to manipulate the } \\
\text { independent variable } \\
\text { - Contamination from extraneous } \\
\text { variables can be controlled more } \\
\text { effectively than in other designs } \\
\text { - Replication of an experiment with } \\
\text { different subject groups and conditions }\end{array}$ & $\begin{array}{l}\text { - Hawthrone effect } \\
\text { - Require a lot of control so that the variables } \\
\text { that are causing changes to occur can be } \\
\text { isolated } \\
\text { - There are limits to the types of manipulation } \\
\text { and controls that are ethical } \\
\text { - Generalization from nonprobability samples } \\
\text { can pose problems despite random } \\
\text { assignment }\end{array}$ \\
\hline $\begin{array}{l}\text { Quasi- } \\
\text { experiment }\end{array}$ & $\begin{array}{l}\text { - Less expensive } \\
\text { - Require fewer resources } \\
\text { - More generalizable } \\
\text { - Better external validity }\end{array}$ & $\begin{array}{l}\text { - Do not allow researchers to have full control } \\
\text { over the treatment exposure or influence of } \\
\text { extraneous variables }\end{array}$ \\
\hline $\begin{array}{l}\text { Structured } \\
\text { questionnaire }\end{array}$ & $\begin{array}{l}\text { - Permit more direct comparability of } \\
\text { responses } \\
\text { - Can address more specific issues }\end{array}$ & $\begin{array}{l}\text { - Interviewer's neutrality has to be } \\
\text { maintained } \\
\text { - Lack the flexibility that is likely to produce } \\
\text { truly creative or novel explanations }\end{array}$ \\
\hline
\end{tabular}

- Results can be easily interpreted

- Cost advantages over focus groups and depth interviews

Interview $\quad$ Gain considerable insight from each individual

- Good for understanding unusual behaviors

- More valid results

Focus group

- Respondents sometimes feed on each other's comments to develop ideas

- Can be done quickly

- More valid results

- Interviewer's age, sex, style of dress, tone of voice, facial expressions, or other non-verbal characteristics may have some influence on a respondent's answers

- Social desirability bias is high

- Results are dependent on the researcher's interpretation

- Uses extensive amounts of interviewer time

- Social desirability bias is high

- Results are not generalizable

Table 1.

Advantages and

- Require objective, sensitive, and effective moderators

(continued) 
Research

\begin{tabular}{|c|c|}
\hline methods & Advantages \\
\hline $\begin{array}{l}\text { Printed } \\
\text { materials }\end{array}$ & $\begin{array}{l}\text { - Easily accessible } \\
\text { - Low cost } \\
\text { - An entire entity can be investigated in } \\
\text { depth with meticulous attention to detail }\end{array}$ \\
\hline Public data & $\begin{array}{l}\text { - Easily accessible } \\
\text { - No cost }\end{array}$ \\
\hline Website data & - Easily accessible \\
\hline $\begin{array}{l}\text { User-generated } \\
\text { data }\end{array}$ & - Easily accessible \\
\hline Objective data & $\begin{array}{l}\text { - Can be unobtrusive } \\
\text { - Can yield actual behavior } \\
\text { - Patterns }\end{array}$ \\
\hline Simulation & $\begin{array}{l}\text { - Critical situations can be investigated } \\
\text { without risk } \\
\text { - Conditions can be varied and outcomes } \\
\text { investigated }\end{array}$ \\
\hline
\end{tabular}

Disadvantages

- Information can be outdated

- May need a lot of cleaning to filter out the required data

- Difficult to mine the required data

- Can be very expensive with participantobserver series

- Can be expensive

- A thorough understanding is needed and an awareness of all the factors involved

- It may be difficult to interpret the simulation results
Research method of hospitality research

Note(s): For a more detailed discussion, please see Cooper and Schindler (2014), Zikmund et al. (2013)

Table 1.

concerns on whether paid participants can provide high-quality data. Table 2 lists the major data sources used in hospitality research. Given the changes in data sources, this study asks

$R Q 2$. What were the data sources used in the 2010s?

\section{Research methods and data sources by functional areas}

To provide a refined understanding of research topics and methods used, some researchers focused their content analysis on one functional area within hospitality research marketing (e.g. Line and Runyan, 2012; Oh et al., 2004; Yoo et al., 2011). These studies found that most marketing studies published between 2000 and 2010 use empirical field surveys. The results were in line with Morosan et al. (2014), which suggested a paradigm shift in hospitality marketing research in 1989-2013 to focus on empirical research with a change in the research method. Unfortunately, content analyses including a method component are rarely seen in other functional areas, including finance, strategy, operations, technology and HR.

Since each functional area has its research evolution, boundaries and field/disciplinespecific expectations (Henning et al., 2005), a content analysis of hospitality marketing research may not inform the general development of hospitality research. Aside from differences in norm and tradition developments, functional areas may use different research methods and data sources because of data availability and measurement levels (Li and Ryerson, 2019). For example, studies focusing on strategy and finance study organizational profitability as outcomes may need to rely on organizational level data, making it difficult to rely on research methods that use primary data (e.g. experiments and surveys) ( $\mathrm{Li}$ and Ryerson, 2019). It suggests a need to extend Baloglu and Assante (1999) and Rivera and Upchurch (2008) by comparing the research method and data sources used in the different functional areas in the 2010s.

$R Q 3$. What were the research methods and data sources used in each functional area in the 2010s? 


\section{IHR}

\begin{tabular}{|c|c|c|c|c|c|c|}
\hline Data sources & Example & Definitions & $\begin{array}{l}\text { Diverse } \\
\text { sample }\end{array}$ & $\begin{array}{l}\text { Measure- } \\
\text { ment } \\
\text { flexibility }\end{array}$ & Cost & $\begin{array}{l}\text { Possible } \\
\text { method }\end{array}$ \\
\hline Student data & Students & $\begin{array}{l}\text { Data are collected } \\
\text { from students or } \\
\text { participants are } \\
\text { recruited by } \\
\text { students' contacts }\end{array}$ & Low & High & Low & $\begin{array}{l}\text { Survey, } \\
\text { experiment, } \\
\text { qualitative, } \\
\text { objective data }\end{array}$ \\
\hline Panel data & MTurk & $\begin{array}{l}\text { Participants are } \\
\text { recruited by } \\
\text { research firms or } \\
\text { from third-party } \\
\text { organizations that } \\
\text { have a group of } \\
\text { selected research } \\
\text { participants }\end{array}$ & Medium & High & Medium & $\begin{array}{l}\text { Survey, } \\
\text { experiment, } \\
\text { qualitative }\end{array}$ \\
\hline $\begin{array}{l}\text { Organizational } \\
\text { data }\end{array}$ & $\begin{array}{l}\text { Employee } \\
\text { data from one } \\
\text { organization }\end{array}$ & $\begin{array}{l}\text { Collaboration with } \\
\text { one or more } \\
\text { organizations to } \\
\text { recruit } \\
\text { participants from } \\
\text { organizational } \\
\text { lists of employees/ } \\
\text { customers }\end{array}$ & Medium & Medium & Medium & $\begin{array}{l}\text { Survey, } \\
\text { experiment, } \\
\text { qualitative, } \\
\text { objective data, } \\
\text { stimulation }\end{array}$ \\
\hline $\begin{array}{l}\text { User-generated } \\
\text { data }\end{array}$ & Reviews & $\begin{array}{l}\text { Data that are } \\
\text { pulled from crowd- } \\
\text { sourcing content } \\
\text { platform }\end{array}$ & High & Low & Low & Archival data \\
\hline Public data & $\begin{array}{l}\text { Financial } \\
\text { reports }\end{array}$ & $\begin{array}{l}\text { Data that are } \\
\text { pulled from } \\
\text { publicly available } \\
\text { data sources, such } \\
\text { as financial } \\
\text { reports, } \\
\text { government and } \\
\text { websites }\end{array}$ & Medium & Low & Low & Archival data \\
\hline $\begin{array}{l}\text { Personal } \\
\text { contacts }\end{array}$ & $\begin{array}{l}\text { Industry } \\
\text { experts } \\
\text { identified by } \\
\text { the } \\
\text { researchers }\end{array}$ & $\begin{array}{l}\text { Data that collected } \\
\text { from people who } \\
\text { are of direct or } \\
\text { indirect contact } \\
\text { with the } \\
\text { researchers }\end{array}$ & Low & High & Medium & $\begin{array}{l}\text { Survey, } \\
\text { experiment, } \\
\text { qualitative, } \\
\text { objective data }\end{array}$ \\
\hline Random data & $\begin{array}{l}\text { Tourists in a } \\
\text { destination }\end{array}$ & $\begin{array}{l}\text { Participants are } \\
\text { recruited by } \\
\text { researchers } \\
\text { randomly at } \\
\text { locations of } \\
\text { interests }\end{array}$ & Medium & High & Medium & $\begin{array}{l}\text { Survey, } \\
\text { experiment, } \\
\text { qualitative }\end{array}$ \\
\hline $\begin{array}{l}\text { Mixed data } \\
\text { sources }\end{array}$ & & $\begin{array}{l}\text { Multiple data } \\
\text { sources are used }\end{array}$ & \multicolumn{4}{|c|}{ It depends on the data sources used } \\
\hline
\end{tabular}

\section{Geographic regions}

Language barriers, cultural differences and differences in researchers' expertise and training can change the use patterns of research methods in different geographic regions (Henning et al., 2005; Kozak et al., 2004). Law et al. (2012) and Shen et al. (2018) focused on author affiliation location and the country keywords in research published in 2008-2011 and 
2002-2011. They found that geographic regions are related to the topics studied, the statistical technique used and the research intensity and development. They also showed that hospitality research primarily used data collected from North America and Asia. Morosan et al. (2014) noted a shift in the geographic data source in hospitality marketing research. However, as globalization increases in the 2010s, there is rapid development in the hospitality industry in Africa and Latin America (Benzitouni and Wawira, 2019; Schmitt and Cruz, 2018). As both Law et al. (2012) and Shen et al. (2018) focused on research published before 2011, it can be interesting to assess whether hospitality researchers have taken advantage of the globalization trends and collect data from different geographic regions.

$R Q 4$. What was the geographic focus of data collection by hospitality researchers in the 2010s?

\section{Research methods and data sources per geographic regions}

Due to differential development, geographic representation provides better insights into assessing the evolution of research (cf. Law et al., 2012; Shen et al., 2018). Some studies focused on the content analysis in a specific country or geographic region, arguing that language barriers limit the exchange of information and research approaches among international scholars (Evren and Kozak, 2014; Huang and Hsu, 2008; Köseoglu et al., 2015; Mehmetoglu, 2004; Tsang and Hsu, 2011). Education and linguistics may also influence the changes in the method used (Shen et al., 2018). For example, non-English-native speakers may prefer sending quantitative over qualitative studies to the five studied journals because of the difficulties translating participants' in-depth responses (Van Nes et al., 2010; Rahman, 2020). Data availability also varies across geographic regions (Amarante, 2014). This is particularly true with the use of panel data. For example, MTurk has been overrepresented by US and Indian users (O'Brochta and Parikh, 2021). At the same time, the online panels are rarely represented in geographic regions with poor Internet access, such as Africa and Latin America (Amazon Mechanical Turk, 2017). Therefore, we take a global focus to extend these studies concentrating on a single region/country (Evren and Kozak, 2014; Huang and Hsu, 2008; Mehmetoglu, 2004; Tsang and Hsu, 2011) and compare the research method and data sources in different geographic regions.

RQ5. What were the research methods and data sources used in each geographic region in the 2010s?

\section{Method}

Journals and articles selection

This study analyzed the research method used by the articles published in the five hospitality journals (CQ, IJHM, IJCHM, JHTR, IHR) from 2010 to 2019. In this section, we describe how we gathered data for the study. We first define our research scope. Next, we describe the coding methods. Based on the above discussions, we ask five questions, including

$R Q 1$. What were the research methods used in the 2010s?

$R Q 2$. What were the data sources used in the 2010s?

$R Q 3$. What were the research methods and data sources used in each functional area in the 2010s?

RQ4. What was the geographic focus of data collection by hospitality researchers in the 2010s?

RQ5. What were the research methods and data sources used in each geographic region in the 2010s?
Research method of hospitality research

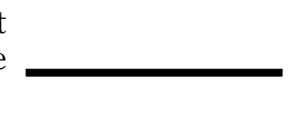


Consistent with Baloglu and Assante (1999), we narrowed our content reviews in these five hospitality journals (CQ, IJHM, IJCHM, JHTR and IHR) for four reasons. First, because tourism and hospitality research differ in the unit of analysis and the data availability, we limited our scope to hospitality research and excluded tourism journals (e.g. Annals of Tourism Research, Tourism Management). Second, we focused on hospitality journals with a general focus and excluded some functional-specific journals, such as the Journal of Hospitality and Tourism Education and the Journal of Hospitality and Tourism Technology. All five journals specify that they welcome research from all functional areas, such as marketing, finance, HR, strategy, operations and technology. Third, all the journals are wellestablished. Using the same set of journals by Baloglu and Assante (1999) also allows a direct comparison of the results in this decade (2010-2019) and the 1990s (1990-1996). Finally, all of these five journals welcome submissions of all research methods.

\section{Coders and validity of coding}

We analyzed the content systematically. First, three researchers developed the coding scheme in an initial meeting. Then, to ensure the accuracy and validity of coding, two researchers coded each article. Finally, inconsistencies were resolved by a discussion among the three researchers.

\section{Coding method}

Empiricalvs conceptual. Researchers manually coded the articles in five steps. In the first step, we identified the articles to be analyzed and only included original empirical hospitality articles and research notes. Excluding editorial, there were 3,227 articles published between January 2010 and December 2019 in the five hospitality journals. After excluding 48 research method papers, 110 destination tourism papers, 199 literature reviews and 108 conceptual papers, we retained a total of 2,759 original hospitality empirical articles for this content analysis.

Coding research method and data sources. In the second step, we coded the research method into (1) mixed method, (2) survey, (3a) scenario experiment, (3b) field experiment, (3c) quasi-experiment, (4a) structured questionnaire, (4b), interview, (4c) focus group, (5a) printed materials, (5b) public data, (5c) website data, (5d) user-generated data, (6) objective data and (7) simulation based on the definition in Table 3. We also coded the data sources into (1) student data, (2) panel data, (3) organizational data, (4) user-generated data, (5) public data, (6) personal contacts, (7) random data and (8) mixed data sources based on the definition in Table 2. Finally, we noted the number of empirical studies in each article. Most articles $(2,628)$ have one study, and 131 articles have multiple empirical studies. Among the 131 multi-studies articles, 50 articles used mixed methods, and 81 used the same methods. Additionally, 20 of the 131 multi-studies articles used mixed data sources, while the other 111 used the same data sources.

Coding functional areas. In the third step, we identified the functional areas. Following Baloglu and Assante (1999), we classified articles into six functional areas: marketing, finance, strategy, operations, technology and HR. Table 4 lists the definitions of each functional area, the editors' functional backgrounds and the distribution of articles. To ensure consistency in coding and avoid overlaps in functional areas, we coded the functional areas based on the study's dependable variables. For example, a study investigating the factors that increase customer satisfaction (e.g. Choi and Chui, 2001) was considered a marketing study. In contrast, a study investigating factors driving employee behaviors (e.g. Curtis et al., 2013) was classified as a human resources study.

Coding geographic regions. Fourth, we coded the studies' geographic regions. We manually coded regions based on major continents: Africa, Europe, Asia (which includes 
$\underline{\text { Research methods }}$

Mixed method

Survey

Experiment: scenario

Experiment: field

Experiment: quasiexperiment

Qualitative: Structured questionnaire

Qualitative: interview

Qualitative: focus group

Archival: printed materials

Archival: public data

Archival: website data

Archival: user-generated data

Objective data

Simulation
Definitions

Research that uses two or more research methods

Research that uses scales to measure respondents' and raters' perceptions, attitudes and behaviors

Research that randomly assigns functionals into experimental conditions and asks respondents to react based on a fictional case, plot and scenes

Research that randomly assigns functionals into experimental conditions and asks respondents to react based on experience

Research that assigns functionals into different conditions and asks respondents to react based on the conditions without random assignment

Research that uses a list of pre-set open-ended questions to understand respondents' attitudes and behaviors; all participants receive the same list of questions and respond individually

Research that asks respondents questions on a topic area in an unstructured one-on-one format; researchers can ask follow-up questions

Research that asks a group of respondents questions on a topic area and allows the group to discuss a topic

Research in which researchers code data using news articles and library resources on a particular case

Research that uses archival, publicly available data collected from financial institutions, annual reports and government data

Research that uses website meta-data (e.g. time spent on the website, hit count, website traffic) and/or data available on a website (e.g. hotel price, locations) Research that collects data users inputted content (e.g. online review)

Research that observers keep track of the data in the respondents' natural environment using machines and company records (e.g. air quality index, heart rate, slot machine pay rate)

Research that uses computer-generated data and data modeling techniques to test model

Note(s): Please see Baloglu and Assante (1999), Arendt et al. (2012) for full discussion
Research method of hospitality research 
IHR

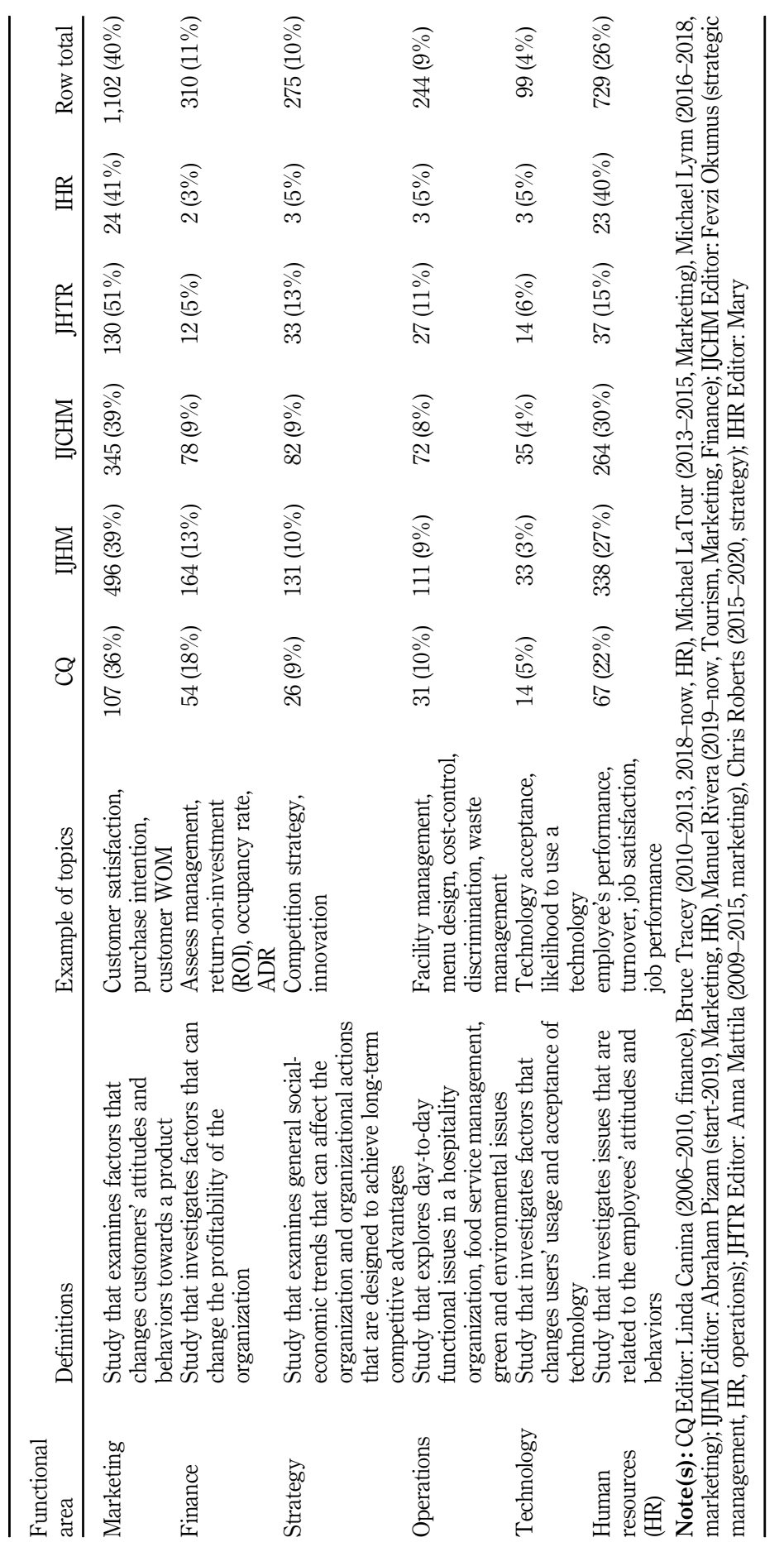

Table 4.

Definitions of functional area 
technology (ranging from 3\% [33 articles, IJHM] to 6\% [14 articles, JHTR]). On the other hand, IHR published almost $40 \%$ of HR articles (23 articles), higher than the other four journals (ranged from 15\% [37 articles, JHTR] to 30\% [264 articles, IJCHM]).

\section{Research methods' usages in the 2010s}

RQ1 focused on the research method used in the 2010s. Table 5 illustrates the research method used in the last decade. Survey research increased sharply in the early 2010s from $44 \%$ in 2010 (78 articles) to $55 \%$ in 2013 (152 articles), followed by a stable period in the rest of 2010s ranging from 51 to $48 \%$ in 2014-2019 (128-237 articles). Overall, 51\% of analyzed articles used survey designs (i.e. 1,401 articles).

Archival data were the second popular research method (593 articles, $22 \%$ of all articles), comparable to the results in the 1990s (19\%, Baloglu and Assante, 1999). While the use of public data, including data from financial markets and census data, decreased to $13 \%$ (363 articles), new forms of archival data - namely web data (3\%,79 articles) and user-generated data $(4 \%, 116$ articles) - played a more prominent role in empirical hospitality research. Although archival data remained relatively stable over time, there were some changes in the sub-categories. While the use of printed materials and public data decreased over time, there were more published articles using web data and user-generated data. In particular, the number of studies using user-generated data, such as online reviews, increased from 3 articles ( $2 \%$ of the published articles in 2010) to 42 articles ( $9 \%$ of the published articles in 2019).

Experiments were the third popular research method (11\% of all articles, 318 articles). There was also a strong positive correlation between the total number of studies and the percentage of the experiment study $(r=0.69, p<0.05)$. Scenario experiment was the most popular among the three different types of experiments $(8 \%, 225$ articles), followed by quasi-experiment $(2 \%, 56 \%)$ and field experiment $(1 \%, 37$ articles). Specifically, the representation of scenario experiments doubled over the years (from 4\% [7 articles] in 2010 to $8 \%$ [41 articles] in 2019).

Around $9 \%$ of the published articles (235 articles) used a qualitative method. Among all three qualitative methods (structured questionnaire, interview and focus group), interviews were the most popular, with 200 published articles (7\% of all articles). The number of qualitative studies decreased in the first half of the 2010s, dropping from 27 articles $(16 \%)$ in 2010 to 14 articles $(6 \%)$ in 2014. However, the number of qualitative studies increased in the latter half of the 2010 s, representing $9 \%$ of the articles published in 2018 ( 29 articles) and 2019 (42 articles).

Similar to previous studies (e.g. Baloglu and Assante, 1999; Law et al., 2012), there was only a handful of studies using objective data (1\%, 40 articles) and simulation $(1 \%, 14$ articles). Around $6 \%$ of the published articles used a mixed method design. However, the portions of mixed method articles decreased from $10 \%$ in 2010 (18 articles) to only 6\% in 2019 (29 articles). The total number of publications published in a year was negatively related to the percentage of mix-method studies $(r=-0.56, p<0.1)$.

\section{Data sources used in the 2010 s}

Figure 1 answers RQ2, which investigates the use of data sources in the 2010 s. Half (50\%) of the studied articles use organizational data (1,368 articles), making it the most used data source. However, organizational data usage decreased from 58\% (104 articles) to 35\% (174 articles), while panel data increased from 3\% (5 articles) to $24 \%$ (118 articles) over time. Although public data dropped from a high of $21 \%$ in 2010 (38 articles) to $12 \%$ in 2016 (32 articles), it slowly recovered to $18 \%$ in 2019 (93 articles). User-generated data increased from $1 \%$ ( 2 articles) to $8 \%$ (40 articles) over the 2010 s, indicating the increasing reliance on this new

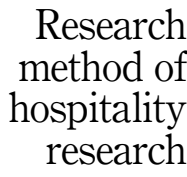


IHR

Table 5.

Research methods over time

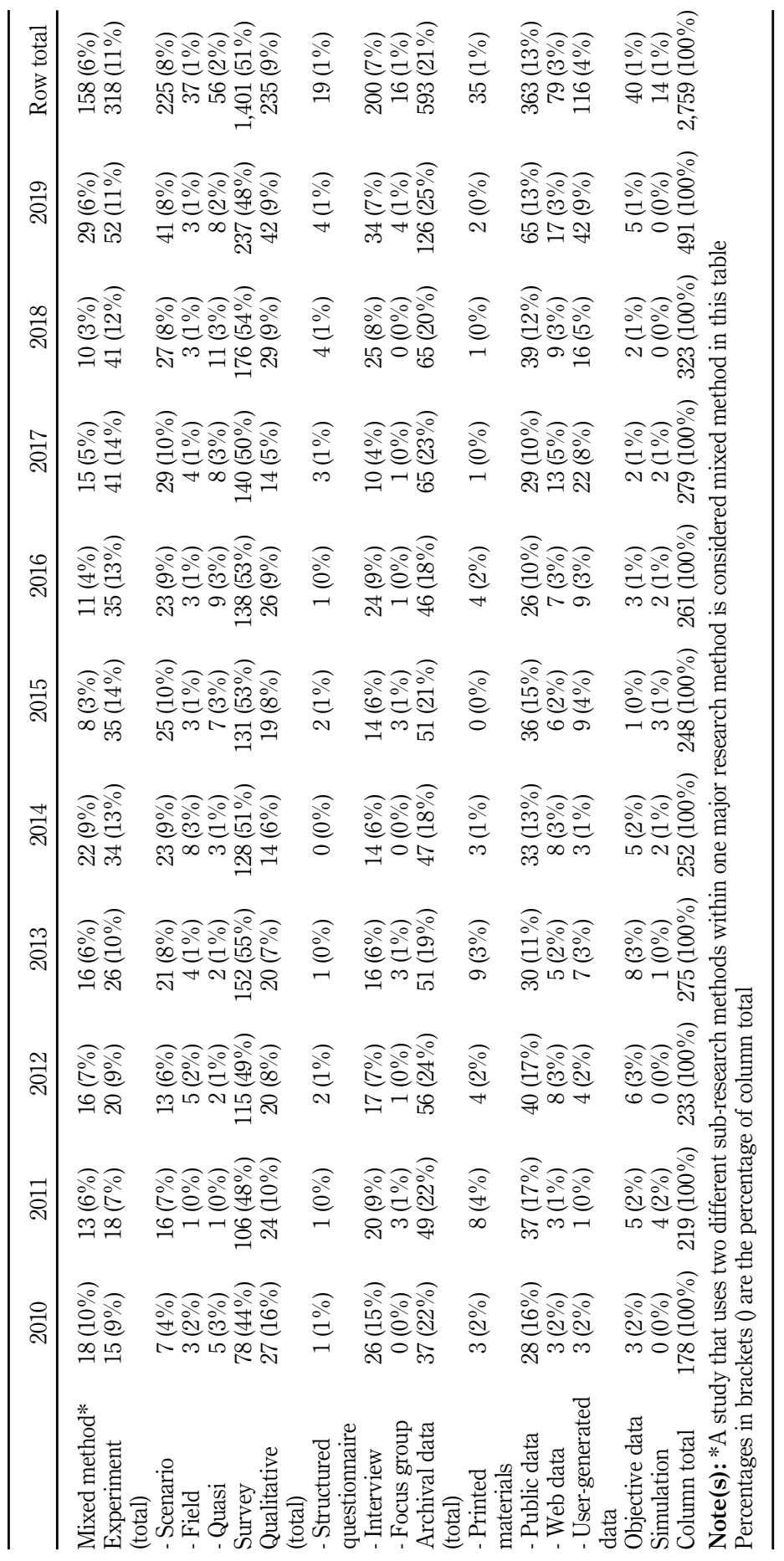




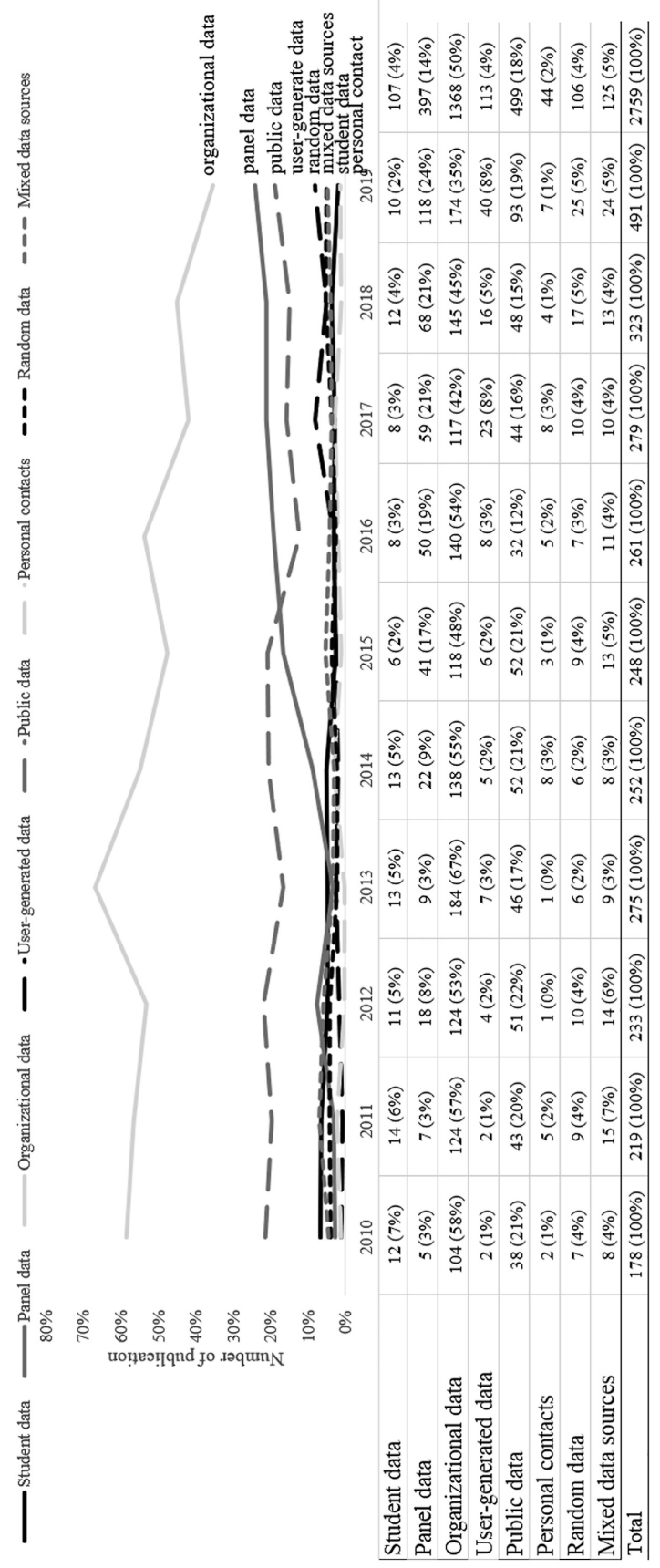

Research method of hospitality research 

articles). Other data sources, including personal contact (2\%, 44 articles), random data ( $4 \%$, 106 articles) and mixed data sources (5\%,125 articles), remain to be used in less than $5 \%$ of articles in 2010s.

\section{Functional areas}

To further understand the above results, we analyzed how the functional areas of original hospitality empirical research changed over time (see Figure 2). Marketing was the most popular functional area (40\%, 1,102 articles). The portion of marketing articles increased from $33 \%$ in 2010 (59 articles) to 44\% in 2019 (214 articles). HR were the second most popular functional area, accounting for 25\% (729 articles) of all articles. However, HR articles decreased from $32 \%$ (57 articles) to $24 \%$ (118 articles) over the 2010 s. The portion of finance (11\%, 310 articles), strategy $(10 \%, 275$ articles) and operations $(9 \%, 244$ articles) articles remained relatively stable over time. In the 2010 s, there was a slight increase in technology articles from $2 \%$ in 2010s ( 4 articles) to $4 \%$ in 2019 (21 articles). However, technology remains the least popular functional area (4\%,99 articles) in the 2010 s. In short, although there are more articles published in each year $\left(r_{\text {year-total number of articles }}=0.80, p<0.05\right)$, marketing research contributes to most of the increases $\left(r_{\text {year-total number of marketing articles }}=0.88, p<0.05\right)$.

\section{Research methods by functional areas}

Figure 3 addresses RQ3 by showing the research methods by functional areas. Functional areas were related to research method usage $\left.\chi_{\mathrm{df}=65}^{2}=039.05, p<0.01\right)$. Operations was the only functional area that used all seven research methods, including $29 \%$ surveys $(70$ articles), $27 \%$ archival data (65 articles), 19\% qualitative methods (47 articles), $9 \%$ objective data ( 22 articles), $6 \%$ experiments ( 15 articles) and $3 \%$ simulations ( 7 articles). Additionally, $7 \%$ (18 out of 244 ) of the operations articles used mixed method designs.

Similarly, marketing articles used a wide range of methods, including $5 \%$ mixed method (60 articles), 53\% surveys (584 articles), 24\% experiments (260 articles), 12\% archival data (133 articles) and $5 \%$ qualitative methods (51 articles). The increasing number of marketing studies over time (see Figure 2) and the diverse methods used in marketing articles (see Figure 3) may explain the rise of experiment and user-generated data over time. Indeed, $83 \%$ (260 out of 315) of the experimental studies and $80 \%$ (93 out of 115) of the user-generated data were marketing articles.

The diversity of research methods used in operations and marketing articles strongly contrasts with finance articles, which predominantly used archival data (84\%, 261 articles). Moreover, $73 \%$ (227 articles) of finance articles use only one category of archival data - public data. Indeed, $63 \%$ (227 out of 360) of the public data articles were finance articles. A small portion of the finance articles used surveys $(8 \%, 26$ articles) and qualitative methods $(2 \%$, 6 articles). Around $3 \%$ of finance articles (10 articles) used a mixed method design. Only one finance article used experiments, making it the field with the fewest articles that employed experiments.

Similarly, HR articles did not use diverse research methods. Over $76 \%$ of HR articles (551 articles) used surveys, while $11 \%$ (78 articles) used qualitative methods. With only $5 \%$ of HR articles (35 articles) used experiments, experimental designs were not common in HR articles. There was only $5 \%$ (35 articles) used a mixed method design. Only $4 \%$ of HR articles (29 articles) used archival data. There were no HR studies that used objective data, and only $1 \mathrm{HR}$ study used simulations.

Strategy and technology articles shared a similar pattern in the research method. Such that the top three methods were surveys (42\% [115 out of 275 strategy articles]; $57 \%$ [ 56 out of 99 technology articles]), archival data (33\% [92 out of 275 strategy articles]; $16 \%$ [16 out of 99 


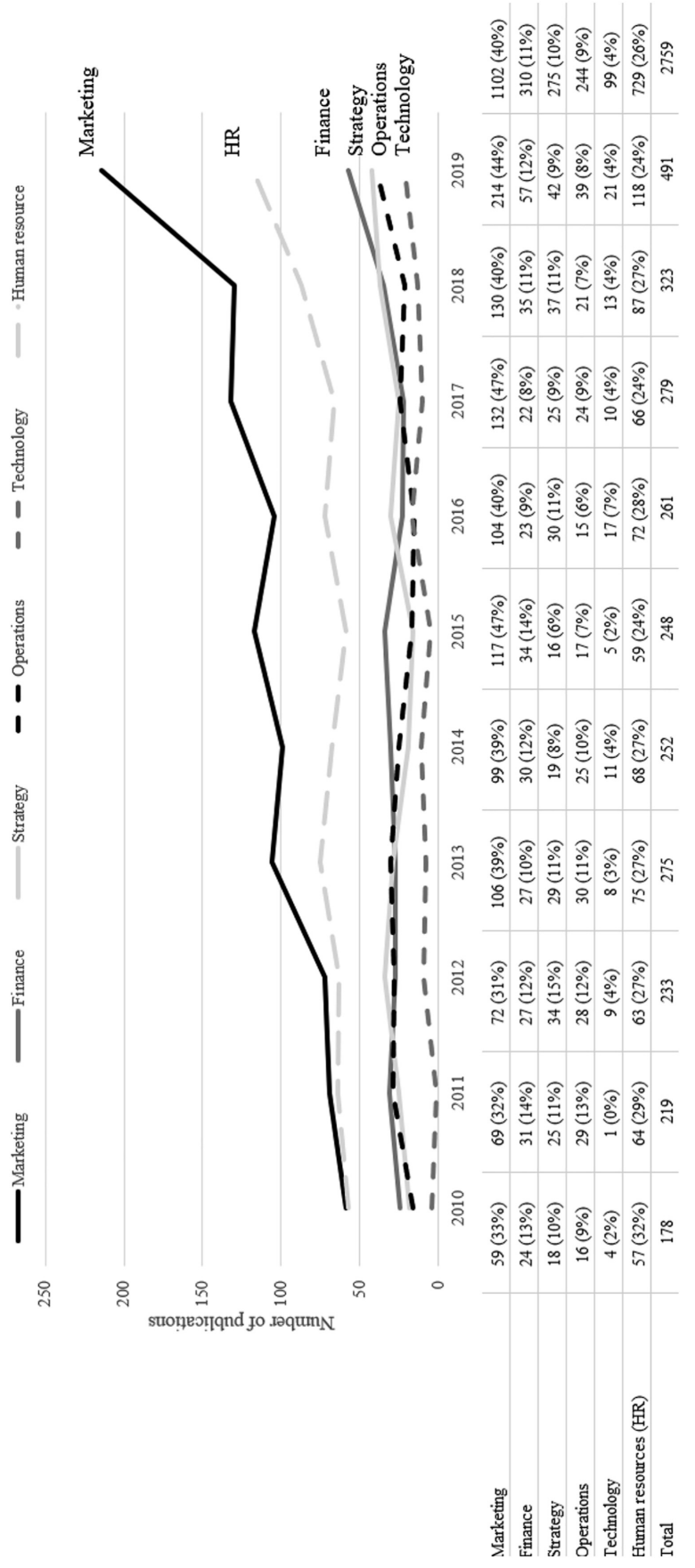

Research method of hospitality research 


\section{IHR}

Figure 3.

Research method by functional areas

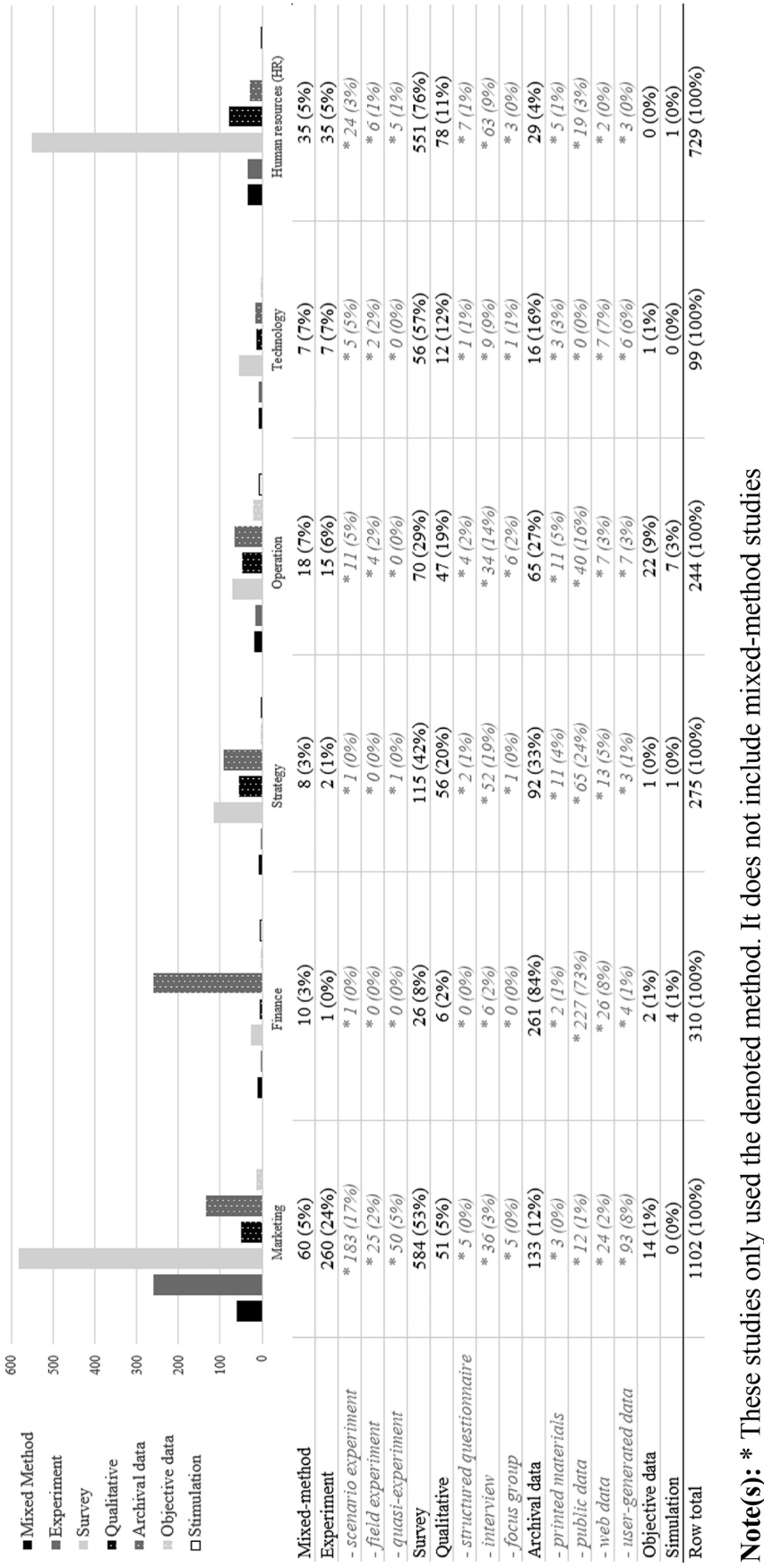


technology articles]), and qualitative methods (20\% [56 out of 275 strategy articles]; $12 \%$ [12 out of 99 technology articles]). However, $24 \%$ (65 out of 275) of strategy articles used public data versus none of the technology articles used public data. Conversely, 16/275 (6\%) of strategy articles versus 13/99 (13\%) of technology articles used web data and usergenerated data.
Research method of hospitality research

\section{Data sources by functional areas}

As shown in Figure 4, functional areas of research were related to the data sources. With marketing research had a good mix of different research methods, it also used diverse data sources. Organizational and panel data were most popular, accounting for $46 \%$ (503 articles) and $24 \%$ (266 articles) of marketing articles, respectively. However, marketing articles also use other data sources, including public data (7\%, 82 articles), user-generated data $(7 \%, 73$ articles), student data (5\%, 57 articles) and personal contact $(1 \%, 13$ articles). There were also $4 \%$ of marketing articles ( 46 articles) that used mixed data sources.

Organizational data were most commonly used in HR studies (74\%, 543 articles). Around $8 \%$ of HR studies (59 articles) used panel data, $5 \%$ (38 articles) used student data and $5 \%$ (36 articles) used public data. However, other data sources, including random data $(1 \%, 9$ articles), personal contacts ( $1 \%, 8$ articles) and user-generated data (1\%, 4 articles), were seldomly used. Only 4\% of HR studies (32 articles) used mixed data sources.

Since finance mainly uses archival data as a research method, public data were the most commonly used data source $(73 \%, 226$ articles). In addition, there were $14 \%$ of finance studies (44 articles) used organizational data. Finance studies seldom use other data sources, including user-generated data (5\% 16 articles), mixed data sources (4\%, 12 articles), panel data (3\%, 10 articles) and random data (1\%, 2 articles). No finance studies used personal contact or student data. The top four data sources used in technology studies were organizational data (34\%, 34 articles), panel data (29\%, 29 articles), user-generated data (10\%, 10 articles) and public data (10\%, 10 articles). The usage of student data (5\%, 5 articles),

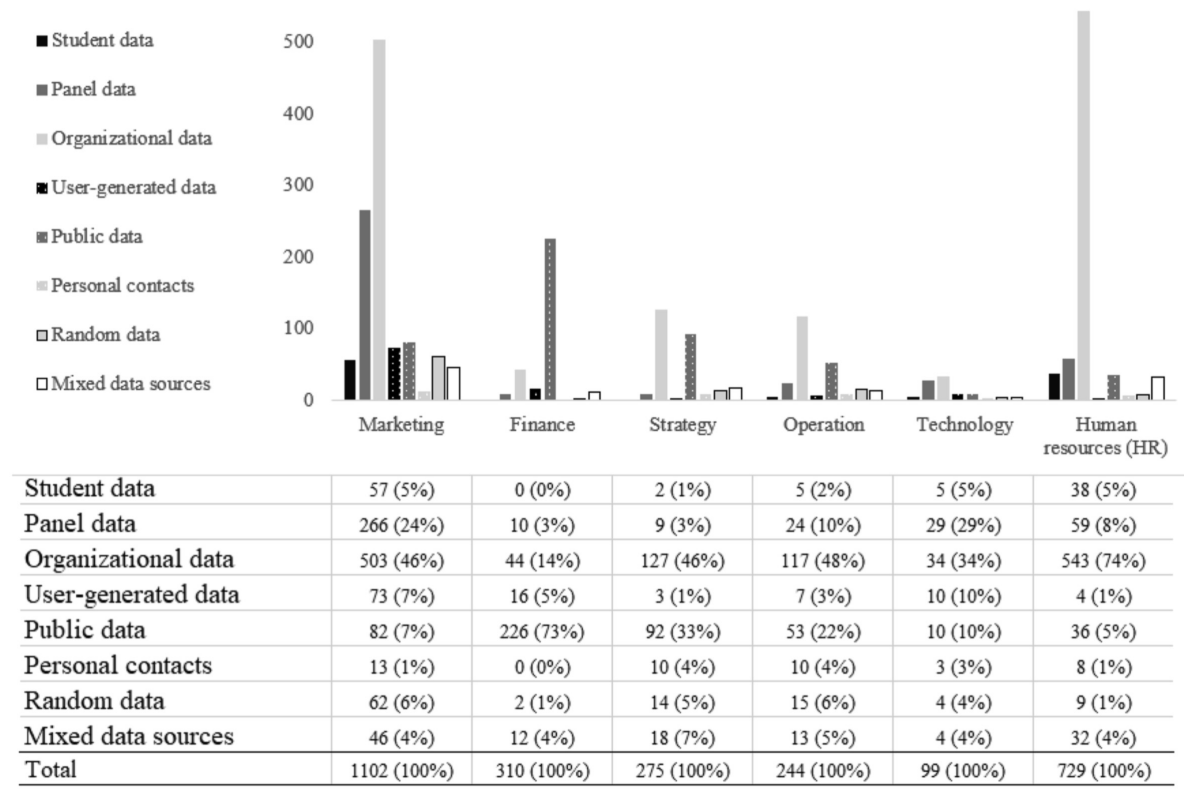

Figure 4. Data sources by functional areas 
random data (4\%, 4 articles) and personal contacts (4\%, 4 articles) were not common in technology articles. There were also only $4 \%$ of technology articles ( 4 articles) that used mixed data sources.

Both strategy and operations studies feature the use of organizational data (strategy: $46 \%$ [127 articles]; operations: 48\% [117 articles]) and public data (strategy: 33\% [92 articles]; operations: $22 \%, 53$ articles). Strategy and operations studies seldom used random data (strategy: 5\%,14 articles; operation: 6\%,15 articles), personal contact (strategy: 4\%, 10 articles; operation: $4 \%, 10$ articles) and student data (strategy: $1 \%, 2$ articles; operations: $2 \%$, 5 articles). While panel data were not common in strategy ( $3 \%, 9$ articles), it was common in operations $(10 \%, 24$ articles). Mixed data source was also uncommon in strategy $(7 \%, 18$ articles) and operation (5\%, 13 articles).

\section{Geographic regions overtime}

RQ4 investigates the research intensity in different geographic regions. Despite increased emphasis on globalization, Table 6 showed that the portion of studies conducted in the various geographic regions remained relatively stable over time. Results showed that most articles used data from North America (1,119 articles, 41\%) and Asia (979 articles, 35\%). European data articles increased slowly from $12 \%$ (22 articles) in 2010 to $16 \%$ (77 articles) in 2019. Overall, there was $14 \%$ of the articles used European data (387 articles). Unfortunately, there was only a handful of studies using data from Oceania ( $3 \%, 94$ articles), Africa $(1 \%, 37$ articles) and Latin America (1\%, 19 articles) in the 2010s. Less than ten articles were from Latin America and Africa each year, representing around 0-2\% of the analyzed articles. There was a drop in multi-region articles from 2010 ( $6 \%, 10$ articles) to 2014 ( $2 \%, 6$ articles). However, the number of multi-regions articles increased steadily since 2015 ( $4 \%, 11$ articles). As a result, 7\% of the 2019 articles (33 articles) used data collected from two or more geographic regions.

\section{Research methods by geographic regions}

Figure 5 answers RQ5 by showing the research method used in different geographic regions. Geographic regions had different research method usage patterns $\chi^{2} \mathrm{df}=91=572.74$, $p<0.01$ ), suggesting that the usage of hospitality research can differ across geographic regions. It is worth noting that user-generated data were collected from all six geographic areas and contributed $10 \%$ of the multi-region articles (13 articles).

Researchers used a variety of methods to collect data from North America. It had a low reliance on survey research $(40 \%, 453$ articles) and has a good mix of experiments $(20 \%, 223$ articles) and archival data (28\%, 311 articles). It also used all other methods, including qualitative studies ( $5 \%, 56$ articles), objective data (2\%, 25 articles) and simulation $(1 \%, 5$ articles). Indeed, researchers collected $62 \%$ (223 out of 360) of the public data studies from North America.

Despite the relatively low usage of experiments $(7 \%, 26$ articles), data collected from Europe originates from a good mix of methods, including survey $(43 \%, 168$ articles), archival data $(29 \%, 114$ articles) and qualitative studies (14\%, 54 articles). Furthermore, it also contributes to the usage of mixed method ( $5 \%, 19$ articles), objective data ( $1 \%, 4$ articles) and simulation (1\%, 2 articles). Thus, the results indicating that the development of the research methods was quite sophisticated in Europe. Interestingly, Oceania had the lowest reliance on surveys (37\%, 35 articles) and the highest reliance on qualitative studies ( $25 \%, 24$ articles). Similar to North America and Europe, Oceania also had a good balance of experiments $(13 \%$, 12 articles), archival data (16\%, 15 articles) and objective data (3\%, 3 articles).

Although Asia also used all research methods, it relied on surveys ( $67 \%, 660$ articles). On the other hand, there was a relatively small portion of archival data $(12 \%, 114$ articles), 


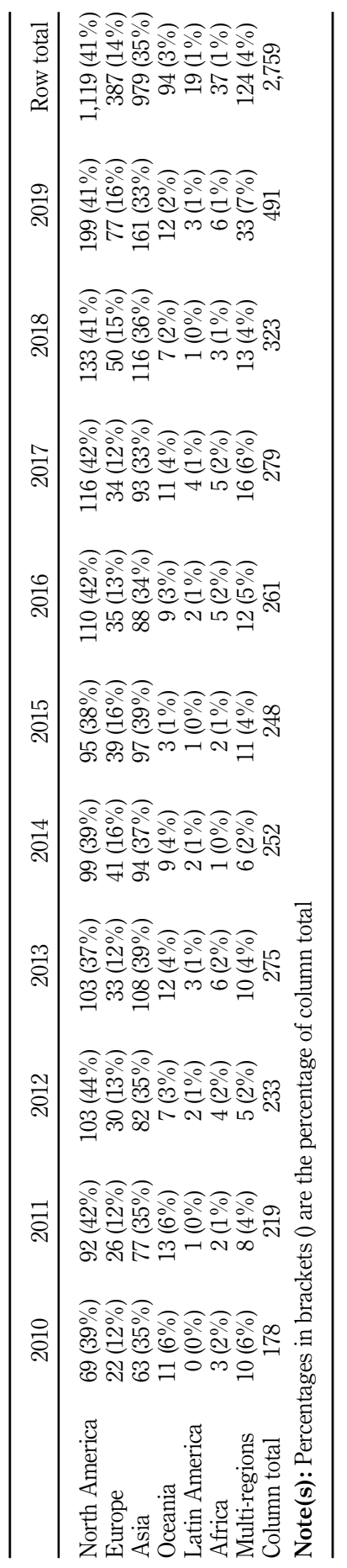

Research method of hospitality research 


\section{IHR}

Figure 5.

Research method by geographic regions

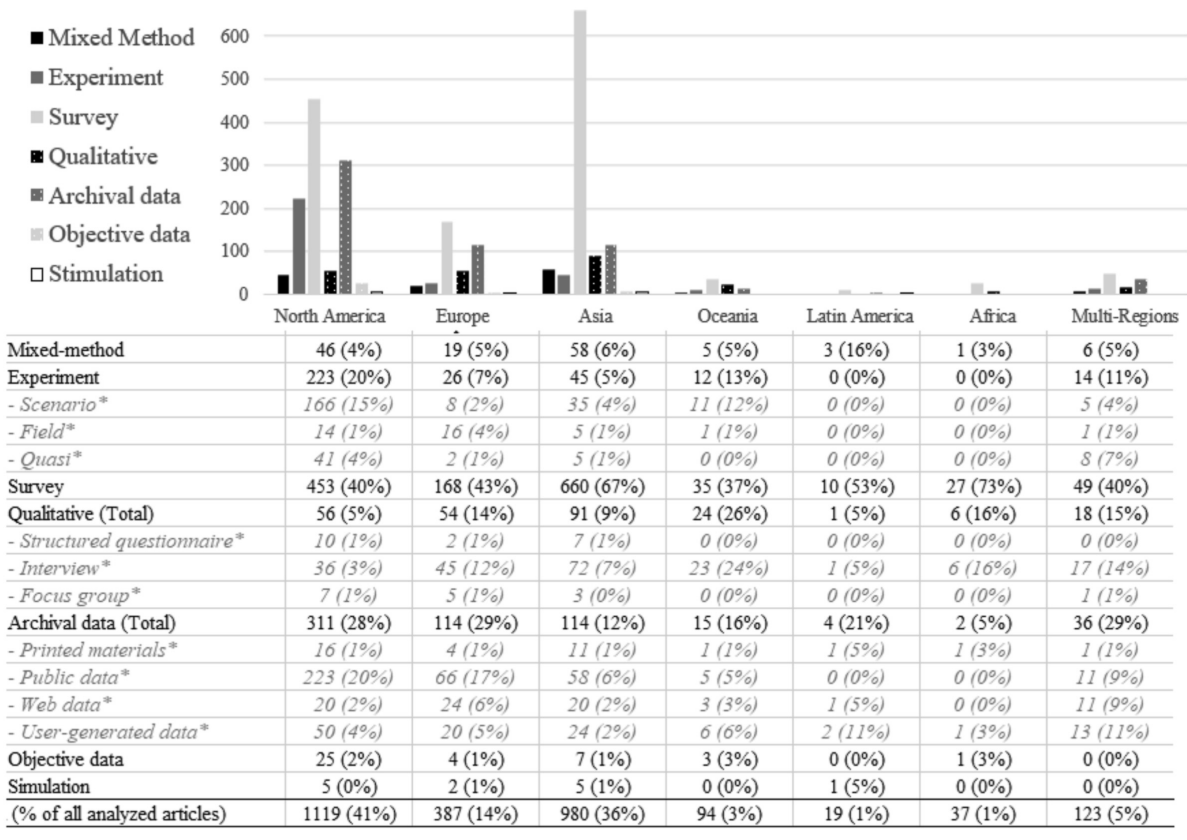

Note(s): * These studies only used the denoted method. Therefore, it does not include mixed-method studies

qualitative studies ( $9 \%, 54$ articles), mixed method studies $(6 \%, 19$ articles), experiments $(5 \%$, 26 articles), objective data (1\%, 4 articles) and simulation (1\%, 2 articles). Such reliance on survey research was similar to other developing regions, such as Latin America (53\%, 10 articles) and Africa (73\%, 27 articles). Researchers collected archival data (21\%, 4 articles) and a mixed method study (16\%, 3 articles) in Latin America. On the other hand, some qualitative studies were collected in Africa (16\%, 6 articles). Only one qualitative study (5\%) and one simulation (5\%) were collected from Latin America. Similarly, researchers only collected one mixed method study $(3 \%)$, one objective data $(3 \%)$ and two archival data $(3 \%)$ in Africa. However, no experiment was collected from Latin America or Africa.

\section{Data sources by geographic regions}

Table 7 illustrates the data sources by geographic regions. Although North America and Asia contribute the most data, the types of data they contribute can be very different. For example, while North America contributes the most student data (64\%, 69 out of 107 articles), panel data $(76 \%, 300$ out of 397 articles) and public data (52\%, 257 out 499 articles), Asia contributes the most organizational data ( $50 \%, 687$ out of 1,368 articles), personal contacts (59\%, 26 out of 44 articles) and random data (48\%, 51 out of 106 articles). Of the 133 studies using user-generated data, $46 \%$ originated from North America (52 articles), 19\% from Europe (22 articles), 18\% from Asia (20 articles), 4\% from Oceania (4 articles), $2 \%$ from Latin America ( 2 articles) and $1 \%$ from Africa (1 article). Researchers also collected $11 \%$ of the usergenerated data from multi-region (11 articles), indicating that it can be possible to conduct multi-region research. In the next section, we discuss the implications of the result of this study and make recommendations for the journal editors, researchers and institutions. Additionally, we address the limitations of this project. 


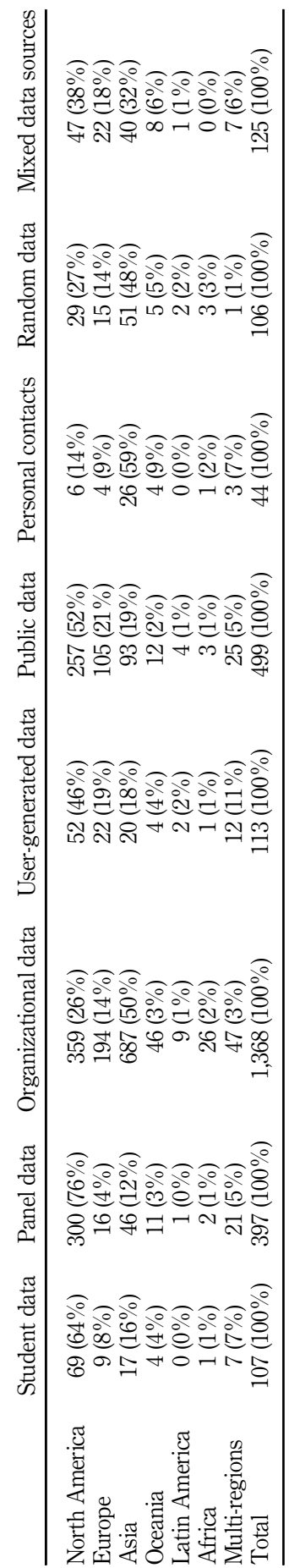

Research method of hospitality research

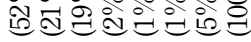

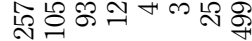

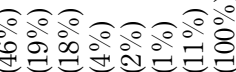
종ำ

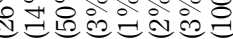

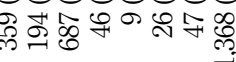

Table 7.

Data sources by geographic regions 
This study analyzed research methods and data sources of 2,759 original hospitality research articles published in the top five hospitality journals from 2010 to 2019. As research methods can be a proxy of research rigor, they illuminated the overall progression of the research development. By focusing on five journals, six functional areas and seven geographic regions over the last decade, we showed that hospitality research had developed significantly over the last decade. First, the results indicate a continuing trend of increasing empirical studies in hospitality research: the portion of empirical studies increased from 32\% in 1990-1996 (Baloglu and Assante, 1999, which analyzed the same five journals) to $82 \%$ in 2000-2005 (Rivera and Upchurch, 2008, which focused on IJHM only) and 85\% in 2010-2019 as selected in this study.

As technology had enabled new research methods (e.g. user-generated data) and new data sources (e.g. online panel data), there was growing diversity in the research methods employed. There was a slight increase in qualitative research in the mid-2010s. This change could be attributed to the launching of designated special qualitative sections in IJHM in 2018 (Elsevier, 2017), indicating that journals' special issues can impact researchers' method choices. Recent calls of specific research methods, such as experiments (Fong et al., 2016) and user-generated data (Lu and Stepchenkova, 2015), increased the usage of these methods and decreased reliance on the survey. However, as in the 1990s (Baloglu and Assante, 1999), objective data and simulation remain minimal, suggesting potential new avenues. Thus, the research method and data sources usage depend on journal editorial decisions and the calls from prolific scholars.

Overall, these results suggested that hospitality research in the 2010 s was more advanced and diversified than in previous decades. The portion of survey studies across the 2010s was significantly lower than previously reported (e.g. Baloglu and Assante, 1999; Law et al., 2012). Compared with Baloglu and Assante (1999), which use the same list of five journals, the reliance on surveys dropped from 80 to $51 \%$ during the period of 1990-2010s. However, surveys remained to be the most popular research method in the 2010s. While hospitality research was using the new technology-enabled method, such as website data and usergenerated information, the use of objective data and simulation remains minimal.

However, the technology also results in new threats, as seen in the decreased usage of organizational data and increased reliance on panel data. One possible reason is the availability of online panels, such as Amazon MTurk, Qualtrics Panels and SurveyMonkey online panels. Although panel data provide easy access to the diverse sample (MTurk, 2017), organizational data can provide richer contexts for researchers to understand the implications of the studies.

The developing trend of using diverse methods was not the same in all functional areas. Similar trends can be seen in the data sources because data sources and research methods are highly related. Together, the results showed that functional area was related to the research method used, and each functional area varied in terms of developments in research techniques. Unfortunately, the results indicate that some functional areas develop faster than other functional areas. While marketing and operational research contribute to the diversity of the research method used, other functional areas, such as HR and finance, continued to use the same method (survey with organizational data; archival data with public data) as in the 1990s. Because finance and HR were the second and third most popular functional areas, the primary usage of archival data in finance articles and surveys in HR articles may explain the popularity of survey and public data in all hospitality research.

Compared with Shen et al. (2018), our results showed that the geographical landscape of hospitality research did not change much over the years - the majority of the studies used data from North America and Asia. Oceania, Latin America and Africa remained underrepresented in the five hospitality journals focused on this research. The results 
indicate that the findings yield in hospitality research from these five journals may be more applicable to North America and Asia. However, the findings from these five journals may have limited generalizability to developing geographic regions, such as Oceania, Africa and Latin America. One plausible explanation would be that most established hospitality schools are in the USA, Asia, and Europe, and all five journals are US-based. Geographic regions were related to the research method used, which may be attributed to the training and the differential norms of the preferred method in the culture (Shen et al., 2018). Geographic regions also provide different data sources. Aside from language and training, the differences across geographic regions can be attributed to legal requirements (Benoit et al., 2019). For example, while getting data from organizations in North America requires corporate legal approval, getting such data in Asia is usually a regional office decision (Benoit et al., 2019). Similarly, although most North American publicly traded organizations are required to share their financial information, the sharing requirements can be different in Asia (SEC, 2020). However, user-generated data across all geographic regions suggest that this new research method can be a potential avenue for collecting data in different geographic regions, which may be difficult for traditional research methods.

Finally, due to the difficulties of using a mix-method or collecting data from multiple geographic areas, only a small portion of articles used mixed method (6\%, 158 articles) or collected data from multiple geographic regions (4\%, 124 articles). Unfortunately, this suggests that the hospitality research method has not improved significantly since previous content analyses work in the past two decades (e.g. Baloglu and Assante, 1999; Law et al., 2012). Therefore, as researchers, we need to spark new conversations by diversifying our research methods and study designs. Drawing on the above findings, we made a few recommendations to the hospitality editors and researchers.

\section{Recommendation for editors: Be open to nontraditional research methods}

To stimulate research method diversity, editors should be more open to other research methods that have seldom been used in the functional areas. For example, several mainstream studies suggested that experimental designs can be utilized to extend finance (e.g. Libby et al., 2002; Karlan, 2005) and HR research (e.g. Aguinis and Bradley, 2014; Podsakoff and Podsakoff, 2019). Therefore, we encourage editors to create a special section on mixed method articles. They can also call for nontraditional methods in special issues (e.g. nonsurvey research in HR or nonarchival data research in finance), thus allowing for exemplar studies that show interesting and potentially different results by using unconventional methods.

\section{Recommendation for researchers: use new tools to conduct research}

It is important to note that each research method diverges in its generalizability, realism and measurement precision (Baloglu and Assante, 1999). Thus, we reiterate Baloglu and Assante's (1999) recommendation for researchers to use multiple research methods in their studies. Specifically, we encourage researchers to consider adding qualitative analysis into quantitative research. For example, researchers can use a qualitative study to showcase the decision-making process and explains quantitative results. We also encourage researchers to use more qualitative research in finance and marketing.

Technology also enables researchers to have more research methods to conduct research. Our results showed that the utilization of user-generated data was on the rise. However, this rise was mainly limited to marketing research. Researchers from other functional areas can learn from their marketing peers and use more user-generated data. For example, HR researchers can use online employee reviews (e.g. Glassdoor and Indeed) to understand employee outcomes (Stamolampros et al., 2020). Similarly, researchers can use traditional

\author{
Research \\ method of \\ hospitality \\ research
}


methods (e.g. qualitative) to analyze data from newer methods (e.g. review comments data from user-generated data).

The use of objective data remains minimal in the 2010s. However, this can be changed with the availability of wearable technology and smart-home technology. For example, operations research can use auto-generated data from smart-home devices (e.g. smart thermostats) to improve operational efficiency (Nadkarni et al., 2019). In addition, by using both traditional methods (e.g. survey and experiment) and newer technology (e.g. wearable technology), researchers test more interesting research questions related to the personal well-being of guests and employees (Massaro and Pecchia, 2019), as well as to understand workplace relationships (Chaffin et al., 2017).

We challenge researchers to consider different data sources. Although technology facilitates the use of online panel data (e.g. MTurk), which provides cheap and easy access to the diverse sample (Aguinis et al., 2021), we encourage researchers to keep using field research (e.g. organizational data) such that researchers would be able to know more contextual information (e.g. organizational background) from organizations and provide practical implications to organizations that provide data access (Tracey, 2020).

\section{Recommendation to institutions: conduct research globally}

Since each culture has its unique values, the findings from one geographic region may not be generalizable to other regions (Hofstede, 2001). Thus, in line with Law et al. (2012), we call for more research in traditionally ignored geographic areas, such as Oceania, Latin America and Africa. In particular, the hospitality industry in Africa and Latin America has developed dramatically in the last few years (Benzitouni and Wawira, 2019; Schmitt and Cruz, 2018). It presents unique HR, strategy and operations research (Aguinis et al., 2020). We recommend interinstitutional collaboration such that seasoned researchers establish research collaborations with local researchers in Latin America and Africa. This will facilitate the progression of hospitality research. Moreover, it will allow researchers to develop culturespecific research in these developing regions.

\section{Limitations and future research}

This study synthesizes the research method used in original hospitality research in the 2010 s. Although we addressed several issues, some other vital issues are out of the scope of this research and warrant future research attention. First, we did not include a content analysis of statistical-related issues due to space constraints, such as sample size, level of measurement and analyses. Future research can compare statistical usage and identify potential analytical recommendations. Second, our content analyses excluded tourism articles and research method articles. Some research methods and data analyses articles provide sample studies to illustrate the method/analyses. Although it only accounts for 48 articles, these articles usually showcase newer methods. Thus, our results may underestimate some of the usages of newer methods. Third, we limited our content analyses to research articles published in five journals. The results cannot be generalized to articles that are not conducted but not accepted in the five journals. It is unclear whether editorial decisions or authors' preferences caused the changes in the method used. Although the five journals have a general focus, the background of editors may change editorial decisions, favoring articles of specific functional areas, research methods and data sources used. A comparison of the journals, SSCI journals and non-SSCI journals may provide a more comprehensive understanding of the hospitality research development in terms of the research methods used.

Fourth, our study focused on a systematic description of the method and data sources usage over time. It does not provide an in-depth description of how the method changes over time. However, empirical studies are getting more sophisticated. For example, survey 
research has changed from a cross-section self-report survey to multi-level, multi-source, multi-wave and longitudinal surveys (Dolnicar, 2018). Similarly, more realism checks are used in experiments (Fong et al., 2016). We encourage future research to focus on each method and describe how the method changes over time. Finally, the COVID-19 pandemic may make some research methods that rely on face-to-face interactions (e.g. face-to-face interview/focusgroup) impossible. Since some organizations can be focusing on dealing with the pandemic, they may be unwilling to collaborate with research, making data collection in organizations more difficult. Future research can expand our study and understand how the COVID-19 pandemic affects the research method used.

\section{References}

Aguinis, H. and Bradley, K.J. (2014), "Best practice recommendations for designing and implementing experimental vignette methodology studies”, Organizational Research Methods, Vol. 17 No. 4, pp. 351-371.

Aguinis, H., Villamor, I., Lazzarini, S.G., Vassolo, R.S., Amorós, J.E. and Allen, D.G. (2020), “Conducting management research in Latin America: why and what's in it for you?", Journal of Management, Vol. 16, pp. 1-22.

Aguinis, H., Villamor, I. and Ramani, R.S. (2021), "MTurk research: review and recommendations", Journal of Management, Vol. 47, pp. 823-837.

Ali, F., Ciftci, O., Nanu, L., Cobanoglu, C. and Ryu, K. (2021), "Response rates in hospitality research: an overview of current practice and suggestions for future research", Cornell Hospitality Quarterly, Vol. 62 No. 1, pp. 105-120.

Amarante, V. (2014), "Income inequality in Latin America: data challenges and availability", Social Indicators Research, Vol. 119 No. 3, pp. 1467-1483.

Amazon Mechanical Turk (2017), "MTurk is now available to requesters from 43 countries", available at: https://blog.mturk.com/mturk-is-now-available-to-requesters-from-43-countries77d16e6a164e.

Arendt, S., Roberts, K., Strohbehn, C., Ellis, J., Paez, P. and Meyer, J. (2012), "Use of qualitative research in foodservice organizations", International Journal of Contemporary Hospitality Management, Vol. 24 No. 6, pp. 820-837.

Baloglu, S. and Assante, L.M. (1999), "A content analysis of subject areas and research methods used in five hospitality management journals", Journal of Hospitality and Tourism Research, Vol. 23 No. 1, pp. 53-70.

Benoit, S., Klose, S., Wirtz, J., Andreassen, T.W. and Keiningham, T.L. (2019), "Bridging the data divide between practitioners and academics: approaches to collaborating better to leverage each other's resources", Journal of Service Management, Vol. 30 No. 5, pp. 524-548.

Benzitouni, A. and Wawira, J. (2019), Hospitality Report Africa 2019, 3rd ed., HospitalityNet, available at: https://www.hospitalitynet.org/file/152008745.pdf.

Chaffin, D., Heidl, R., Hollenbeck, J.R., Howe, M., Yu, A., Voorhees, C. and Calantone, R. (2017), “The promise and perils of wearable sensors in organizational research", Organizational Research Methods, Vol. 20 No. 1, pp. 3-31.

Cheah, J., Sarstedt, M., Ringle, C., Ramayah, T. and Ting, H. (2018), "Convergent validity assessment of formatively measured constructs in PLS-SEM", International Journal of Contemporary Hospitality Management, Vol. 30 No. 11, pp. 3192-3210.

Choi, T.Y. and Chu, R. (2001), "Determinants of hotel guests' satisfaction and repeat patronage in the Hong Kong hotel industry", International Journal of Hospitality Management, Vol. 20 No. 3, pp. 277-297.

Chon, K.S., Evans, M.R. and Sutherlin, D. (1989), "Trends in hospitality management literature: a content analysis", Hospitality Education and Research Journal, Vol. 13 No. 3, pp. 483-491.
Research method of hospitality research

\section{$\longrightarrow$}


Cooper, D.R. and Schindler, P.S. (2014), Business Research Methods, 12th ed., McGraw-Hill Education, New York, NY.

Crawford-Welch, S. and McCleary, K.W. (1992), "An identification of the subject areas and research techniques used in five hospitality-related journals", International Journal of Hospitality Management, Vol. 11 No. 2, pp. 155-167.

Cunill, O.M., Salvá, A.S., Gonzalez, L.O. and Mulet-Forteza, C. (2019), "Thirty-fifth anniversary of the international journal of hospitality management: a bibliometric overview", International Journal of Hospitality Management, Vol. 78, pp. 89-101.

Curtis, C.R., Upchurch, R.S. and Dickson, D. (2013), "Restaurant industry perspectives on pro-social rule-breaking: intention vs action”, Hospitality Review Journal, Vol. 31 No. 1, pp. 1-23.

Dolnicar, S. (2018), "A reflection on survey research in hospitality", International Journal of Contemporary Hospitality Management, Vol. 30 No. 11, pp. 3412-3422.

Elbanna, S. and Gherib, J. (2012), "Miller's environmental uncertainty scale: an extension to the Arab world", International Journal of Commerce and Management, Vol. 22 No. 1, pp. 7-25.

Elsevier (2017), "New IJHM special sections", available at: https://www.journals.elsevier.com/ international-journal-of-hospitality-management/news/new-ijhm-special-sections.

Evren, S. and Kozak, N. (2014), "Bibliometric analysis of tourism and hospitality related articles published in Turkey", Anatolia - An International Journal of Tourism and Hospitality Research, Vol. 25 No. 1, pp. 61-80.

Fong, L., Law, R., Tang, C. and Yap, M. (2016), "Experimental research in hospitality and tourism: a critical review", International Journal of Contemporary Hospitality Management, Vol. 28 No. 2, pp. 246-266.

García-Lillo, F., Úbeda-García, M. and Marco-Lajara, B. (2016), "The intellectual structure of research in hospitality management: a literature review using bibliometric methods of the journal International Journal of Hospitality Management”, International Journal of Hospitality Management, Vol. 52, pp. 121-130.

Henning, G.K., Levy, S. and Ritchie, J.R. (2005), "An inquiry into the nature and composition of tourism, leisure and hospitality research", Tourism, Vol. 53 No. 3, pp. 187-203.

Hofstede, G. (2001), Culture's Consequences: Comparing Values, Behaviors, Institutions and Organizations across Nations, 2nd ed., Sage Publications, Thousand Oaks, CA.

Huang, S. and Hsu, C.H. (2008), "Recent tourism and hospitality research in China", International Journal of Hospitality and Tourism Administration, Vol. 9 No. 3, pp. 267-287.

Jones, C. (2010), “Archival data: advantages and disadvantages for research in psychology”, Social and Personality Psychology Compass, Vol. 4 No. 11, pp. 1008-1017.

Karlan, D.S. (2005), "Using experimental economics to measure social capital and predict financial decisions", American Economic Review, Vol. 95 No. 5, pp. 1688-1699.

Köseoglu, M.A., Sehitoglu, Y. and Craft, J. (2015), "Academic foundations of hospitality management research with an emerging country focus: a citation and co-citation analysis", International Journal of Hospitality Management, Vol. 45, pp. 130-144.

Köseoglu, M.A., Rahimi, R., Okumus, F. and Liu, J. (2016), "Bibliometric studies in tourism”, Annals of Tourism Research, Vol. 61, pp. 180-198.

Kozak, M., Bigné, E. and Andreu, L. (2004), "Limitations of cross-cultural customer satisfaction research and recommending alternative methods", Journal of Quality Assurance in Hospitality and Tourism, Vol. 4 Nos 3/4, pp. 37-59.

Law, R., Leung, D. and Cheung, C. (2012), "A systematic review, analysis, and evaluation of research articles in the Cornell Hospitality Quarterly", Cornell Hospitality Quarterly, Vol. 53 No. 4, pp. 365-381.

Li, M.Z. and Ryerson, M.S. (2019), "Reviewing the DATAS of aviation research data: diversity, availability, tractability, applicability, and sources", Journal of Air Transport Management, Vol. 75, pp. 111-130. 
Libby, R., Bloomfield, R. and Nelson, M.W. (2002), "Experimental research in financial accounting", Accounting, Organizations and Society, Vol. 27 No. 8, pp. 775-810.

Line, N.D. and Runyan, R.C. (2012), "Hospitality marketing research: recent trends and future directions", International Journal of Hospitality Management, Vol. 31 No. 2, pp. 477-488.

Lu, W. and Stepchenkova, S. (2015), "User-generated content as a research mode in tourism and hospitality applications: topics, methods, and software", Journal of Hospitality Marketing and Management, Vol. 24 No. 2, pp. 119-154.

Lynn, M. (2017), "More multi-study articles wanted", Cornell Hospitality Quarterly, Vol. 58 No. 3, pp. 228, doi: 10.1177/1938965517714372.

Mariani, M. and Baggio, R. (2020), "The relevance of mixed methods for network analysis in tourism and hospitality research", International Journal of Contemporary Hospitality Management, Vol. 32 No. 4, pp. 1643-1673.

Massaro, S. and Pecchia, L. (2019), "Heart rate variability (HRV) analysis: a methodology for organizational neuroscience”, Organizational Research Methods, Vol. 22 No. 1, pp. 354-393.

Mattila, A. (2004), "Consumer behavior research in hospitality and tourism journals", International Journal of Hospitality Management, Vol. 23 No. 5, pp. 449-457.

Mehmetoglu, M. (2004), "Quantitative or qualitative? A content analysis of nordic research in tourism and hospitality", Scandinavian Journal of Hospitality and Tourism, Vol. 4 No. 3, pp. 176-190.

Min, H., Park, J. and Kim, H.J. (2016), "Common method bias in hospitality research: a critical review of literature and an empirical study", International Journal of Hospitality Management, Vol. 56, pp. 126-135.

Morosan, C., Bowen, J.T. and Atwood, M. (2014), "The evolution of marketing research", International Journal of Contemporary Hospitality Management, Vol. 26 No. 5, pp. 706-726.

Nadkarni, S., Kriechbaumer, F., Rothenberger, M. and Christodoulidou, N. (2019), "The path to the hotel of things: internet of things and big data converging in hospitality", Journal of Hospitality and Tourism Technology, Vol. 11 No. 1, pp. 93-107.

Oh, H., Kim, B.Y. and Shin, J.H. (2004), "Hospitality and tourism marketing: recent developments in research and future directions", International Journal of Hospitality Management, Vol. 23 No. 5, pp. 425-447.

Olsen, W. (2019), "Bridging to action requires mixed methods, not only randomised control trials", The European Journal of Development Research, Vol. 31 No. 2, pp. 139-162.

O'Brochta, W. and Parikh, S. (2021), “Anomalous responses on Amazon mechanical Turk: an Indian perspective", Research and Politics, Vol. 8 No. 2, pp. 1-4.

Palmer, A.L., Sese, A. and Montano, J.J. (2005), "Tourism and statistics: bibliometric study 1998-2002", Annals of Tourism Research, Vol. 32 No. 1, pp. 167-178.

Podsakoff, P.M. and Podsakoff, N.P. (2019), "Experimental designs in management and leadership research: strengths, limitations, and recommendations for improving publishability", The Leadership Quarterly, Vol. 30 No. 1, pp. 11-33.

Rahman, M.S. (2020), "The advantages and disadvantages of using qualitative and quantitative approaches and methods in language 'testing and assessment' research: a literature review", Journal of Education and Learning, Vol. 6 No. 1, pp. 102-112.

Richard, B., Sivo, S., Orlowski, M., Ford, R., Murphy, J., Boote, D. and Witta, E. (2018), "Online focus groups: a valuable alternative for hospitality research?”, International Journal of Contemporary Hospitality Management, Vol. 30 No. 11, pp. 3175-3191.

Rivera, M.A. and Upchurch, R. (2008), "The role of research in the hospitality industry: a content analysis of the IJHM between 2000 and 2005”, International Journal of Hospitality Management, Vol. 27 No. 4, pp. 632-640.

Schmitt, A. and Cruz, M. (2018), "On the rise: hospitality in Latin America", available at: https:// hospitalityinsights.ehl.edu/hospitality-in-latin-america.

\section{Research method of hospitality research}


SEC (2020), "Disclosure considerations for China-based issuers", available at: https://www.sec.gov/ corpfin/disclosure-considerations-china-based-issuers.

Shen, Y., Morrison, A.M., Wu, B., Park, J., Li, C. and Li, M. (2018), "Where in the world? A geographic analysis of a decade of research in tourism, hospitality, and leisure journals", Journal of Hospitality and Tourism Research, Vol. 42 No. 2, pp. 171-200.

Stamolampros, P., Korfiatis, N., Chalvatzis, K. and Buhalis, D. (2020), "Harnessing the "wisdom of employees' from online reviews", Annals of Tourism Research, Vol. 80, 102694.

Stritch, J.M., Pedersen, M.J. and Taggart, G. (2017), "The opportunities and limitations of using Mechanical Turk (Mturk) in public administration and management scholarship", International Public Management Journal, Vol. 20 No. 3, pp. 489-511.

Tracey, J.B. (2020), “Co-created scholarship”, Cornell Hospitality Quarterly, Vol. 61 No. 2, p. 112.

Truong, D., Liu, R.X. and Yu, J.J. (2020), "Mixed methods research in tourism and hospitality journals", International Journal of Contemporary Hospitality Management, Vol. 32 No. 4, pp. 1563-1579.

Tsang, N.K. and Hsu, C.H. (2011), "Thirty years of research on tourism and hospitality management in China: a review and analysis of journal publications", International Journal of Hospitality Management, Vol. 30 No. 4, pp. 886-896.

Van Nes, F., Abma, T., Jonsson, H. and Deeg, D. (2010), "Language differences in qualitative research: is meaning lost in translation?", European Journal of Ageing, Vol. 7 No. 4, pp. 313-316.

Venkatesh, V., Brown, S.A. and Bala, H. (2013), "Bridging the qualitative-quantitative divide: guidelines for conducting mixed methods research in information systems", MIS Quarterly, Vol. 37 No. 1, pp. 21-54.

Walsh, K. (2003), "Qualitative research: advancing the science and practice of hospitality", Cornell Hotel and Restaurant Administration Quarterly, Vol. 44 No. 2, pp. 66-74.

$\mathrm{Xu}, \mathrm{S}$. and Martinez, L. (2018), "Applications of latent growth curve modeling: a research agenda for hospitality management", International Journal of Contemporary Hospitality Management, Vol. 30 No. 11, pp. 3268-3286.

Yoo, M., Lee, S. and Bai, B. (2011), "Hospitality marketing research from 2000 to 2009: topics, methods, and trends", International Journal of Contemporary Hospitality Management, Vol. 23 No. 4, pp. $517-532$.

Yüksel, A. (2017), “A critique of 'Response Bias' in the tourism, travel and hospitality research", Tourism Management, Vol. 59, pp. 376-384.

Zikmund, W.G., Babin, B.J., Carr, J.C. and Griffin, M. (2013), Business Research Method, 9th ed., Cengage Learning, Mason, $\mathrm{OH}$.

\section{Corresponding author}

Cass Shum can be contacted at: cass.shum@unlv.edu

For instructions on how to order reprints of this article, please visit our website:

www.emeraldgrouppublishing.com/licensing/reprints.htm

Or contact us for further details: permissions@emeraldinsight.com 